Documentación de las Ciencias de la Información

ISSN: 0210-4210

https://doi.org/10.5209/dcin.65270

\title{
El Archivo Histórico Fotográfico de Repsol: Creación y Acceso al material fotográfico
}

\author{
Leticia de Castro Leal ${ }^{1}$
}

Recibido: 9 de mayo de 2019 / Aceptado: 12 de septiembre de 2019

Resumen. Este artículo tiene como objeto analizar la creación del Archivo Histórico de Repsol, elemento fundamental para poder recorrer la historia de los hidrocarburos en España, y el acceso al mismo.

En el texto se abordará primero la forma en la que el sector de los hidrocarburos español operó y se configuró desde la entrada en vigor de la Ley del Monopolio de Petróleos en 1927 hasta la fundación de Repsol en 1987. En la segunda parte del artículo se explorarán tanto la creación del Archivo Histórico Fotográfico de Repsol como los procesos de inventariado, ordenación y conservación que ocurren en él. Se explicarán, también el acceso a dicho archivo y la difusión que desde la compañía se está haciendo del mismo.

Por último, hacer notar también que este artículo obedece a nuestro deseo de hacer del Archivo Histórico de Repsol un recurso que pueda llegar a servir de utilidad a la sociedad. Pero este proceso va a ser todavía largo. Pues a la digitalización de los fondos documentales a un Sistema de Gestión de Archivo se suma también la necesidad de adecuarnos a lo establecido por el Reglamento General de Protección de Datos que entró en vigor en mayo del pasado año.

Palabras Clave: Hidrocarburos - Archivo Histórico - Archivo de Empesa -Repsol - Reglamento General de Protección de Datos.

\section{[en] The Historic Photo Archive of Repsol: creation and access to the digital photography collections}

\begin{abstract}
This article seeks to analyse the creation of Repsol's Historical Archive, an essential tool for understanding the development of the hydrocarbon sector in Spain. The article also explains how to access the aforementioned Archive.

The paper will first examine how the Spanish hydrocarbon sector emerged and how said sector operated after the passing of the Petroleum Monopoly Law in 1927 until Repsol's foundation in 1987. The second part of the article will explore both the creation of Repsol's Historical Archive, specifically its photographic section, and its inventory, filing and conservation processes. In the third section, the paper will explain how access to our archive is controlled and what steps the company is taking to promote it.

Finally, the article addresses Repsol's intention to transform its Historical Archive into a resource for society as a whole. However, this will undoubtedly be a long process, because we have to digitalise our fonds,-or archive groups-, and incorporate them into Repsol's file management system. Futhermore, we have to comply with the General Data Protection Regulation that came into force last May.
\end{abstract}

Key words: Hydrocarbon - Historical Archive - Repsol - General Data Protection Regulation.

\footnotetext{
1 Documentalista en Repsol 1castrol@repsol.com
} 
Sumario: 1. Introducción; 1.1. Actividad: Refino y comercial-Repsol Petróleo; 1.2. actividad: Gas Licuado del Petróleo (GLP) - Repsol Butano; 1.3. actividad: Exploración y producción - Repsol Exploración; 1.4. La reorganización del sector; 2. Archivo Histórico de Repsol; 2.1 Archivo histórico fotográfico de Repsol; 3. Acceso; 3.1. acceso virtual; 4. Conclusiones; 5. Anexo 1. Índice de Abreviaturas; 6. Bibliografía

Cómo citar: Castro Leal, L. de (2019). El Archivo Histórico Fotográfico de Repsol: Creación y Acceso al material fotográfico en Documentación de las Ciencias de la Información, 42, 117-131.

\section{Introducción}

El Archivo Fotográfico Histórico de Repsol (AFHR), se crea al mismo tiempo que el Archivo Histórico de Repsol (AHR), realmente es parte de éste, y es la piedra sobre la que se construye la base de datos multimedia (ALMA) que actualmente existe en Repsol para custodiar material gráfico, y en particular las fotografías que «representan la memoria visual de los siglos XIX y XX y es un medio de representación y comunicación fundamental» (Valle Gastaminza, 1999). ${ }^{2}$

Teniendo en cuenta que se trata de un archivo ${ }^{3}$ histórico, entendiendo este concepto en el contexto de nuestra empresa desde la creación en $1927^{4}$ del Monopolio de Petróleos ${ }^{5}$ hasta 1987 cuando nace Repsol como resultado de la absorción o fusión de varias empresas, es preciso y así lo hemos realizado en otros artículos, que para conocer este periodo y por tanto la historia de nuestra institución, recurramos a los documentos de las empresas de capital público que dieron lugar a Repsol. En estas empresas, las tareas de custodia, de tratamiento archivístico y por supuesto de acceso, se descuidaron hasta el punto de tener almacenes de documentos en lugar de archivos. Si los documentos societarios se destinaron a estos almacenes, todo el material gráfico que acompañaba a esta documentación, también se vio relegada a formar parte de dichos almacenes con la particularidad de ser, en ocasiones, materiales muy frágiles (diapositivas, transparencias o filminas, etc.)

Ante esta perspectiva, creímos necesario crear un archivo histórico que recogiera toda la documentación generada por las diferentes empresas que dieron lugar en 1987 a Repsol y al material gráfico que lo acompaña. Como veremos a continuación los movimientos societarios en este sector han sido innumerables: adquisiciones, fusiones, compra - venta de paquetes accionariales, cambio de denominación social, etc. por lo que se decidió crear una agrupación de fondos en lugar de uno único.

En este artículo haremos un breve recorrido por las empresas que componen el Archivo Histórico de Repsol (AHR) e incorporaremos las fotografías, como tipo documental que ilustran dicho recorrido y que lo enriquecen, aunque no siempre son fáciles de datar.

2 Valle Gastaminza, Félix del. Documentación fotográfica. p. 13.

3 «Conjunto orgánico de documentos o la reunión de varios de ellos reunidos por las personas jurídicas, públicas o privadas en el ejercicio de sus actividades, al servicio de su utilización para la investigación, la cultura, la información y la gestión administrativa. Se entiende también por archivos las instituciones culturales donde se reúnen, conservan, ordenan y difunden para los fines anteriormente mencionados dichos conjuntos orgánicos». Ley 16/1985 del Patrimonio Histórico Español, de 25 de junio. BOE, 155, 29 junio.

4 Real Decreto Ley 1142 Monopolios de Petróleos, de 28 de junio de 1927. Gaceta de Madrid, nº 181, 30 de junio.

5 «Art. 1 El monopolio de petróleos creado por Real Decreto Ley de 28 de junio de 1927 y reorganizado por Ley de 17 julio de 1947 cuya titularidad corresponde al estado queda extinguido». Ley 34/1992 de Ordenación del Sector Petrolero, de 22 de diciembre. BOE, 308 de 24 de diciembre. 


\subsection{Actividad: Refino y comercial- Repsol Petróleo}

En 1927 se crea la Compañía Arrendataria del Monopolio de Petróleos S.A. (campsa), cuya función era la de administrar la concesión del monopolio estatal de petróleos y en 1941 se crea el Instituto Nacional de Industria (INI) ${ }^{6}$. Un año más tarde comenzará la transferencia de funciones del monopolio al INI creándose la primera Empresa Nacional de Combustibles Líquidos y Lubricantes (ENCASO) ${ }^{7}$, constituida como sociedad anónima cuyo ámbito de actividad sería Puertollano.

1927

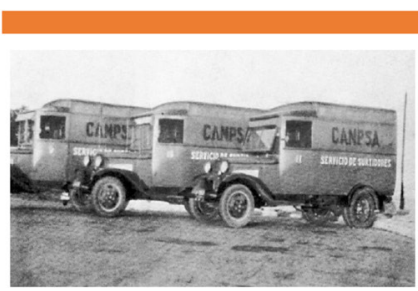

Surtidores CAMPSA.
1933

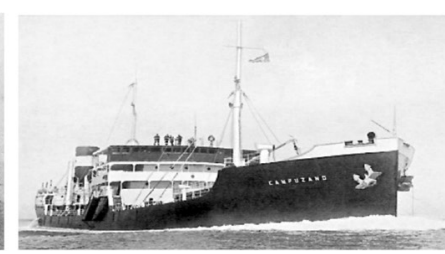

Petrolero Campuzano.
1944

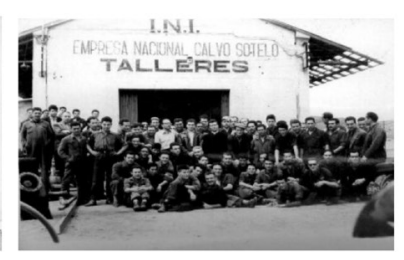

Talleres del INI en Puertollano.

En 1944 se aprueba la Ley sobre el Plan para la Fabricación Nacional de Combustibles Líquidos y Lubricantes e Industrias Conexas ${ }^{8}$, donde se recoge la necesidad de crear industrias para el refino en diferentes lugares de la geografía española. Posteriormente sabremos que éstas son, por orden cronológico de creación: Puertollano, Cartagena, A Coruña y Tarragona.

1944

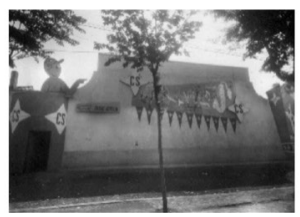

Puertollano

ENCASO

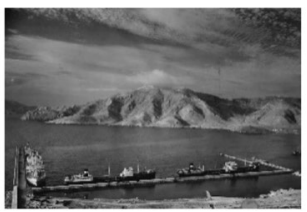

Cartagena

REPESA
1961

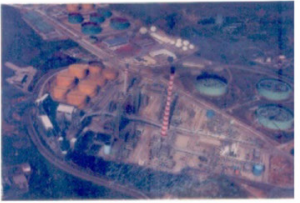

A Coruña PETROLIBER
1971

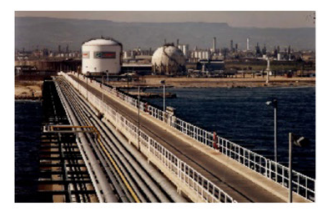

Tarragona

ENTASA

6 Ley de 25 de septiembre de 1941, por la que se crea el Instituto Nacional de Industria (INI). BOE nº 273, de 30 de septiembre.

«Art. 2. El Instituto Nacional de Industria (INI) utilizará los métodos de las Sociedades Anónimas privadas para sus fines estatales, pero conservando siempre en la gestión y administración [...]. Realizará con cargo a sus fondos los trabajos preparatorios para las realizaciones industriales, que el interés de la Nación exija, de los que podrá descargarse al llevarse a cabo la creación de las empresas respectivas».

7 ENCASO. Empresa Nacional Calvo Sotelo de combustibles, líquidos y lubricantes. Creada por Decreto de 22 de enero de 1942, por el que se encomienda al INI la organización de empresas de obtención de carburantes por destilación de pizarras bituminosas. $\mathrm{BOE} \mathrm{n}^{\circ} 34$ de 3 de febrero.

8 BOE $n^{\circ} 148$, de 27 de mayo de 1944. Este plan describía con gran detalle las iniciativas a desarrollar en Puertollano, Levante, Ebro y Puentes de García Rodríguez. 
ENCASO no tiene capacidad por sí misma de llevar a cabo este plan y se sirve del INI para crear empresas que gestionen dichas refinerías. Éstas no serán únicamente de capital público, sino que se dará entrada al capital privado. Esto es gracias a la Ley de Reordenación del Monopolio, donde además «se prescinde del primitivo arrendamiento para sustituirlo por un régimen estatal de desconcentración de servicios reforzando además la intervención estatal en la compañía arrendataria, que continúa siendo CAMPSA» ${ }^{9}$. Para la importación de materias primas, manipulaciones industriales y almacenaje, el Gobierno otorga la facultad a Entidades distintas de la Compañía Arrendataria.

Para el proyecto de la Refinería de Cartagena se constituyó Refinería de Petróleos de Escombreras, S.A. (REPESA ${ }^{10}$ ), quedando fuera del proyecto ENCASO y CAMPSA. En los años 60 surgen cuatro empresas dedicadas a la química: ALCUDIA, CALATRAVA, PAULAR y MONTORO cuya actividad, en un primer momento, se centró en el polipropileno dentro de las instalaciones de la Refinería de Puertollano.

En 1961 se constituye la Compañía Ibérica Refinadora de Petróleos, S.A. (PETROLIBER S.A. ${ }^{11}$ ) creada conjuntamente por Compañía Ibérica de Petróleos, S.A. ${ }^{12}$ y por The Ohio Oil Company, manteniendo el Estado una participación mayoritaria.

El Decreto sobre Refinerías ${ }^{13}$, de 1968 , daba prioridad a la iniciativa privada, quedando el INI relegado a un papel subsidiario, ya que la intervención de dicho instituto se produciría solamente en aquellos casos en que hubiera falta de propuestas privadas. En 1971 se creó la Empresa Nacional de Petróleos de Tarragona, S.A. (ENTASA ${ }^{14}$ ) para la construcción y explotación de la refinería que estaría allí situada. Esta empresa cuenta con una participación del INI del 60\%, el restante será para ERT y diversos bancos.

En este mismo año, se empieza a considerar la reordenación bajo el INI de la iniciativa pública en la actividad energética. Esta iniciativa se materializó tres años después con la fusión de ENCASO, ENTASA Y REPESA, mediante la absorción en esta última de las dos primeras. La empresa resultante pasa a denominarse Empresa Nacional del Petróleo (EMPETROL ${ }^{15}$ ), que en 1986 se fusionará con PETROLIBER y dará lugar a Repsol.

\subsection{Actividad: Gas Licuado del Petróleo (GLP) - Repsol Butano}

En 1957 tomando como ejemplo a las empresas francesas (RAP, SNPA y BRP fusionadas en ELF Aquitaine) CAMPSA y REPESA crean una empresa que se dedicaría a la producción y distribución de GLP, BUTANOSA, Dicho gas había sido quemado, hasta esa fecha en las refinerías. Esta empresa continuará con su forma original hasta

\footnotetext{
Ley de 17 de julio de 1947, por la que se reorganiza el Monopolio de Petróleos. BOE nº 199, de 18 de julio.

10 Participada por el INI, CEPSA y CALTEX el 28 de abril de 1949, para la explotación de la Refinería de Cartagena. Empresa de capital mixto, con mayoría de capital público.

11 Decreto 830/1961, de 9 de mayo. BOE $n^{\circ} 128$ de 30 de mayo.

12 Sociedad dedicada a la investigación de hidrocarburos, cuyos accionistas son el Grupo Fierro, el Banco Exterior de España y el Estados Español, con el 50\%.

13 Decreto 418/1968, de 9 de marzo. BOE nº 61 de 11 de marzo.

14 Decreto 1087/1971, de 14 de mayo. BOE n ${ }^{\circ} 127$ de 28 de mayo.

15 Decreto 2611/1974, de 9 de agosto. BOE no 222, de 16 de septiembre.
} 
que en 1987 pasa a formar parte del grupo Repsol bajo la denominación de Repsol Butano.

\subsection{Actividad: Exploración y producción - Repsol Exploración}

Tras unos comienzos titubeantes de CAMPSA y CEPSA en el sector de la exploración de hidrocarburos, se estableció por ley el Régimen Jurídico de Investigación y Explotación de Hidrocarburos ${ }^{16}$ y su correspondiente desarrollo reglamentario en los años 1958 y 1959. Esta ley vino a rellenar un vacío legal e facilitó las actividades de una serie de empresas internacionales que habían mostrado interés en la investigación de las colonias (Sahara Oriental y Guinea).

En 1965 se crea la sociedad Hispánica de Petróleos, S.A. (HISPANOIL ${ }^{17}$ ), y en 1986 se fusiona ${ }^{18}$ mediante absorción con Empresa Nacional de Investigación y Explotación de Petróleos, S.A. (ENIEPSA), concentrándose así casi la totalidad de los activos públicos en actividades de exploración y producción en una sola empresa, que posteriormente cambiará su denominación a Repsol Exploración.

\subsection{La reorganización del sector}

Como punto de partida, en 1981, se crea mediante Real Decreto Ley el Instituto Nacional de Hidrocarburos (INH) «con el objetivo de coordinar y controlar las actividades empresariales del sector público en el área de los hidrocarburos, así como toda iniciativa empresarial que el sector público promoviera en este campo» ${ }^{19}$. Hasta este momento se habían realizado algunos progresos (fusión de ENCASO, REPESA y ENTASA, creación de ENIEPSA, etc.).

En 1984 y con la vista puesta en el ingreso de España en la $\mathrm{CEE}^{20}$ se transfiere a CAMPSA la red nacional de transporte y logística ${ }^{21}$. El 30 de abril de 1985 el INH vende su participación en CAMPSA a las empresas refinadoras, asignando a cada empresa una participación igual a su participación en las entregas de productos petrolíferos al monopolio.

En 1986 el INH decide crear una sociedad denominada REPSOL S.A. con el objetivo de transferir toda o parte de su participación industrial; que se materializa en junio de 1987, mediante la aportación de su participación en HISPANOIL, BUTANOSA, ENPETROL, CAMPSA y PETRONOR. Pasando así a tener 3 filiales de pleno derecho: Repsol Exploración, Repsol Butano, y Repsol Petróleo, aportando este último otra filial (Repsol Química) y la participación propiedad del INH en CAMPSA y PETRONOR.

\footnotetext{
Ley de 26 de diciembre de 1958. BOE no 311 de 29 de diciembre.

Participada por el INI (50\%), Ibérica de Petróleos (35\%) y Financiera Fierro (15\%).

Orden de 21 de marzo de 1986. BOE n 74 de 27 de marzo.

Real Decreto-Ley 8/1981, de 24 de abril. BOE n 102 de 29 de abril.

20 Para cumplir con los requisitos impuestos por la CEE en este ámbito, se aprueba la Ley 45/1984, de reordenación del sector. BOE $\mathrm{n}^{\mathrm{o}} 302$ de 18 de diciembre.

21 En este contexto CAMPSA pasaría de ser una compañía arrendataria o administradora a ser una auténtica sociedad de distribución.
} 
Estructura societaria del Sector de los Hidrocarburos 1927-1987.

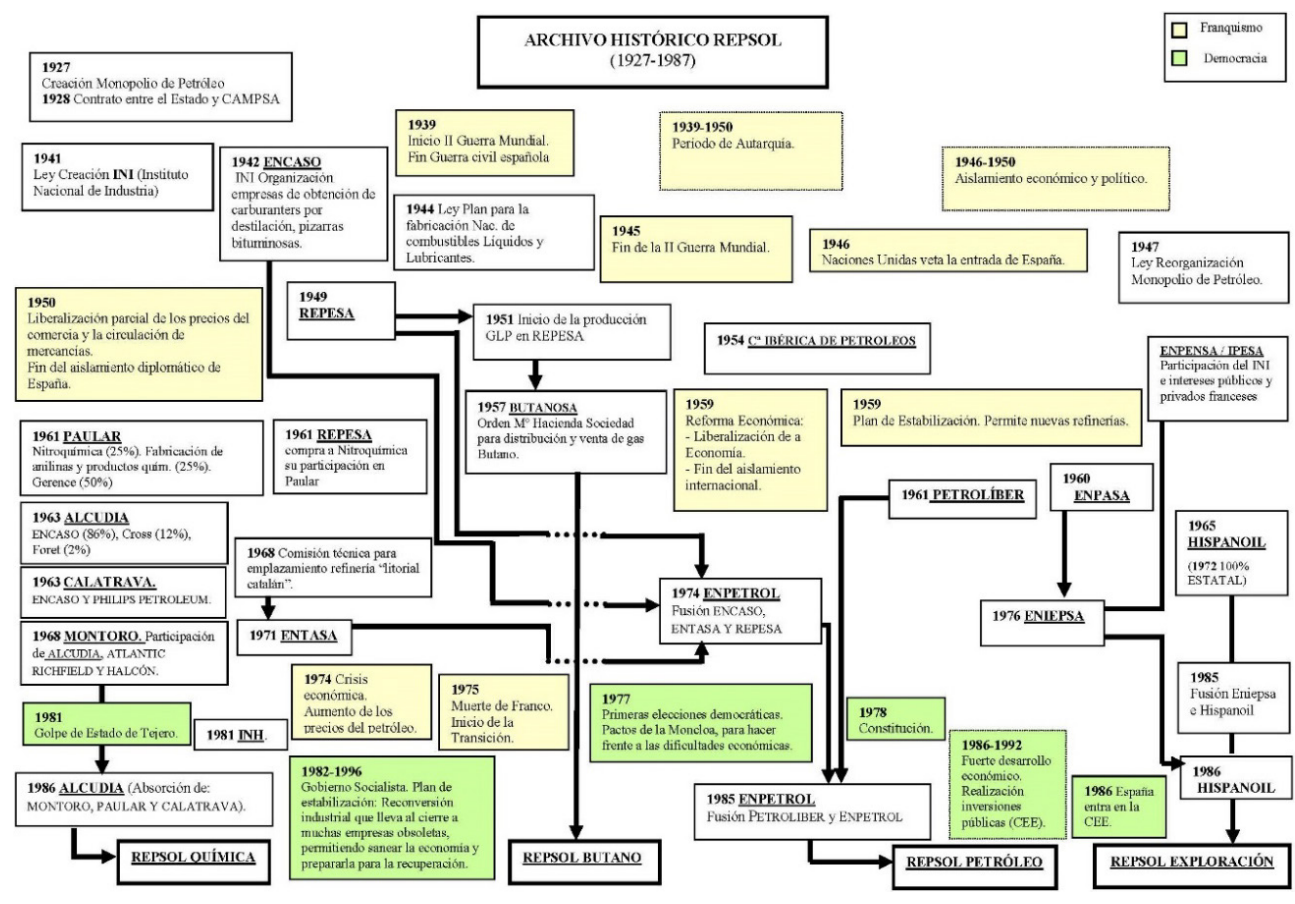

\section{Archivo Histórico de Repsol}

Tenemos ya reconstruida la historia de la empresa Repsol a través de los documentos de archivo. Por tanto el siguiente paso sería la creación de un archivo, adaptado a las necesidades y recursos de dicha empresa, respetando la esencia de la archivística que es básicamente el principio de procedencia.

El carácter cultural y no probatorio es el que aporta valor para que estos documentos conformen las secciones y series de un archivo histórico cuya principal finalidad «es salvaguardar los derechos de la institución que los crea facilitando su gestión, al actuar como memoria y por otra servir como fuentes de elaboración histórica» (Heredia, 1993). Entidades como la SEPI y CLH mantienen archivos históricos, custodios de la actividad de las empresas que han dado lugar a esas organizaciones. El sector de los hidrocarburos contaba hasta hace muy poco tiempo con un vacío que nuestra compañía ha intentado subsanar con la creación a partir del 2005 de un Archivo Histórico.

Estamos haciendo referencia al sector de hidrocarburos entendiendo éste como el conjunto de actividades y productos derivados del petróleo, incluyendo la petroquímica, por tantos las empresas químicas como por ejemplo ALCUDIA son objeto de estudio igualmente. 
Vista la necesidad de contar con un archivo que recogiera la actividad de estas empresas durante gran parte del s. XX, REPSOL acometió esta labor ${ }^{22}$ con entusiasmo.

Solicitamos una subvención al CDTI (Centro para el Desarrollo Tecnológico Industrial) para el proyecto denominado: «Desarrollo de un Sistema de Gestión Documental para el sector de la Exploración, Producción y Comercialización de hidrocarburos $\rangle^{23}$ por la que obtuvimos una ayuda económica que nos permitió abordar este proyecto durante cuatro años.

Por tanto, el archivo de Repsol está formado, como hemos visto por la documentación generada a partir de la actividad de la empresa desde la creación de ENCASO hasta la formación del grupo REPSOL en el año $1987^{24}$. El núcleo del archivo es la documentación societaria (escrituras de constitución, actas de Consejo de Administración, etc.). Al ser conscientes del gran valor que tiene el material gráfico, en especial las fotografías, se creó lo que conocemos como el Archivo Histórico Fotográfico de Repsol (AHFR).

\subsection{Archivo histórico fotográfico de Repsol}

La organización de dicho archivo fue una ardua tarea, y en particular la creación del AHFR, con dos actividades claramente diferenciadas, aunque relacionadas entre sí: descripción y ordenación.

\section{Descripción}

Para la descripción completa de los fondos se empleó la norma ISAD (G) que posibilita la descripción multinivel de todas las partes que lo componen (estructura jerárquica). Paralelamente se llevó a cabo un proceso de inventario / catalogación y digitalización de las imágenes en formato JPG y TIF que veremos a continuación.

\section{- Inventario / Catalogación}

Se realizó un inventario para posteriormente realizar la catalogación del fondo fotográfico de 4015 registros, cuando en la memoria del CDTI se estimaba en 3805 imágenes. Para realizar la catalogación se diseñó una ficha en el sistema de gestión de archivo utilizando los siguientes campos:

22 Se solicita una ayuda - subvención al CDTI para la realización de este proyecto que fue concedida en el año 2006 con una cuantía de aprox. 280.000€. Esta subvención ha posibilitado el avance de este proyecto en el proceso de informatización y digitalización, así como su puesta a disposición de los usuarios a través de la intranet de Repsol (Repsolnet).

23 CDTI. Informe Anual 2006 (http://www.cdti.es/index.asp? MP $=35 \& M S=0 \& M N=1 \& T R=C \& I D R=33 \&$ accion $=$ si\&texto $=\&$ idcategoria $=5 \&$ pag $=10$. Consultado 28/06/2019)

24 REPSOL fue creado por el Instituto Nacional de Hidrocarburos (INH) en 1986. El INH se crea por Ley 45/1981, de 28 de diciembre, siéndole encomendado por el Gobierno la coordinación y control de las actividades empresariales del sector público en el área de los hidrocarburos. Quedó adscrito al Ministerio de Industria y Energía. 
CDTI. Memoria Técnico-Económica del Proyecto denominado:

«Desarrollo de un Sistema de Gestión Documental para el sector de la exploración, producción y comercialización de hidrocarburos».

\begin{tabular}{|c|c|c|c|c|c|}
\hline & Archivo Fotográfico & 167 & & & \\
\hline & & & & & \\
\hline FLD & Nombre & Tipo & Lon. & Oblig & Doc. \\
\hline 1 & $N^{\circ}$ Registro & Entero Largo & - & $N$ & $N$ \\
\hline 2 & Área (F1) & Texto & 25 & $N$ & $N$ \\
\hline 3 & Año & Texto & 4 & $N$ & $N$ \\
\hline 4 & Fecha Captura & Fecha & - & $N$ & $N$ \\
\hline 5 & Histórica (F1) & Texto & 1 & $N$ & $N$ \\
\hline 6 & Formato original (F1) & Texto & 25 & $N$ & $N$ \\
\hline 7 & Formato digital (F1) & Texto & 4 & $N$ & $N$ \\
\hline 8 & Color & Texto & 15 & $N$ & $N$ \\
\hline 9 & Título & Texto & 100 & $N$ & $S$ \\
\hline 10 & Descripción & Texto & 500 & $N$ & $S$ \\
\hline 11 & País (F1) & Texto & 25 & $N$ & $N$ \\
\hline 12 & Provincia (F1) & Texto & 25 & $N$ & $N$ \\
\hline 13 & Palabras Clave (F1) & Texto & 25 & $N$ & $N$ \\
\hline 14 & Observaciones & Texto & 500 & $N$ & $S$ \\
\hline 15 & Licencia de uso (F1) & Texto & 25 & $N$ & $N$ \\
\hline 16 & Ubicación original & Texto & 25 & $N$ & $N$ \\
\hline 17 & Descargas & Entero Largo & - & $N$ & $N$ \\
\hline 18 & Prestado (F1) & Texto & 1 & $N$ & $N$ \\
\hline ID & Clasif. & & & & \\
\hline 1 & 0. Baja resolución < 75 ppp & & & & \\
\hline 2 & 1. Media resolución & & & & \\
\hline 3 & 2. Alta resolución > $300 p p p$ & & & & \\
\hline Campo & Tipo & Nombre Tabla & & & \\
\hline 2 & T. Simple & AF - Area & & & \\
\hline 5 & T. Simple & $1 \mathrm{~S} / \mathrm{N}$ & & & \\
\hline 6 & T. Simple & AF - Formanto Orginal & & & \\
\hline 7 & T. Simple & $A F$ - Formato digital & & & \\
\hline 11 & T. Simple & Pais & & & \\
\hline 12 & T. Jerarquica & Pais - Provincia & & & \\
\hline 15 & T. Simple & $A F$ - Licencia de uso & & & \\
\hline 18 & T. Simple & $1 S / N$ & & & \\
\hline 13 & T. Simple & $A F$ - palabras clave & & & \\
\hline 8 & T. Simple & $A F-$ Color & & & \\
\hline 1 & Num. Auto. & AF - Contador & & & \\
\hline
\end{tabular}

Es importante indicar que el AHFR apenas contiene reportajes. Se trata básicamente de fotografías únicas, de ahí que la labor principal fuese la de identificar y ubicar la fotografía como parte del fondo de la entidad, describir físicamente el documento y describir su contenido. 
Ficha de catalogación del AHFR.

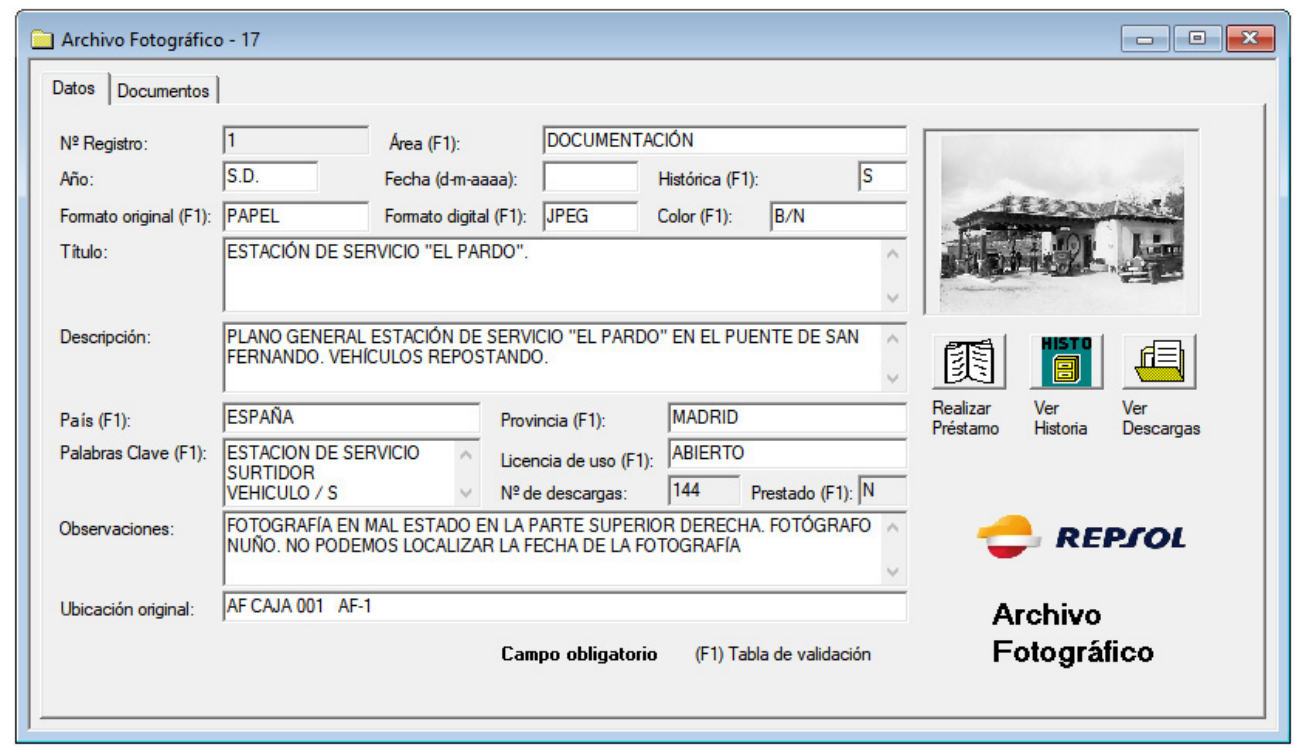

De todos los campos definidos, hay que prestar especial atención al campo Clasificador, que prevé tres formatos de archivo, alta, media y baja resolución (formato digital).

Cuando el documentalista cataloga una fotografía digital y asigna un determinado nivel de clasificación, la aplicación de archivo es capaz de obtener una copia de la imagen en las resoluciones inferiores, archivándola de forma conjunta con el resto de la información. Para ello, en el equipo de registro se instala una aplicación externa de tratamiento de imágenes. El archivador del sistema de gestión de archivo dispone de una macro que, al guardar, revisa los formatos de imágenes disponibles y en el caso de no existir alguno de resolución inferior, invoca mediante parámetros de automatización a la aplicación externa, facilitándole fichero, formato y resolución requerida. La tarea queda a la espera del fichero reconvertido y lo archiva en el lugar correspondiente, procediendo a guardar el registro si no hay más conversiones posibles asociadas al mismo.

Estos desarrollos se implementan mediante macros, tareas programadas y programas desarrollados en Visual Basic y .Net, herramientas de desarrollo admitidas por el programa base. 
Ficha de catalogación del AHFR. Tipos de resolución de la Fotografía.

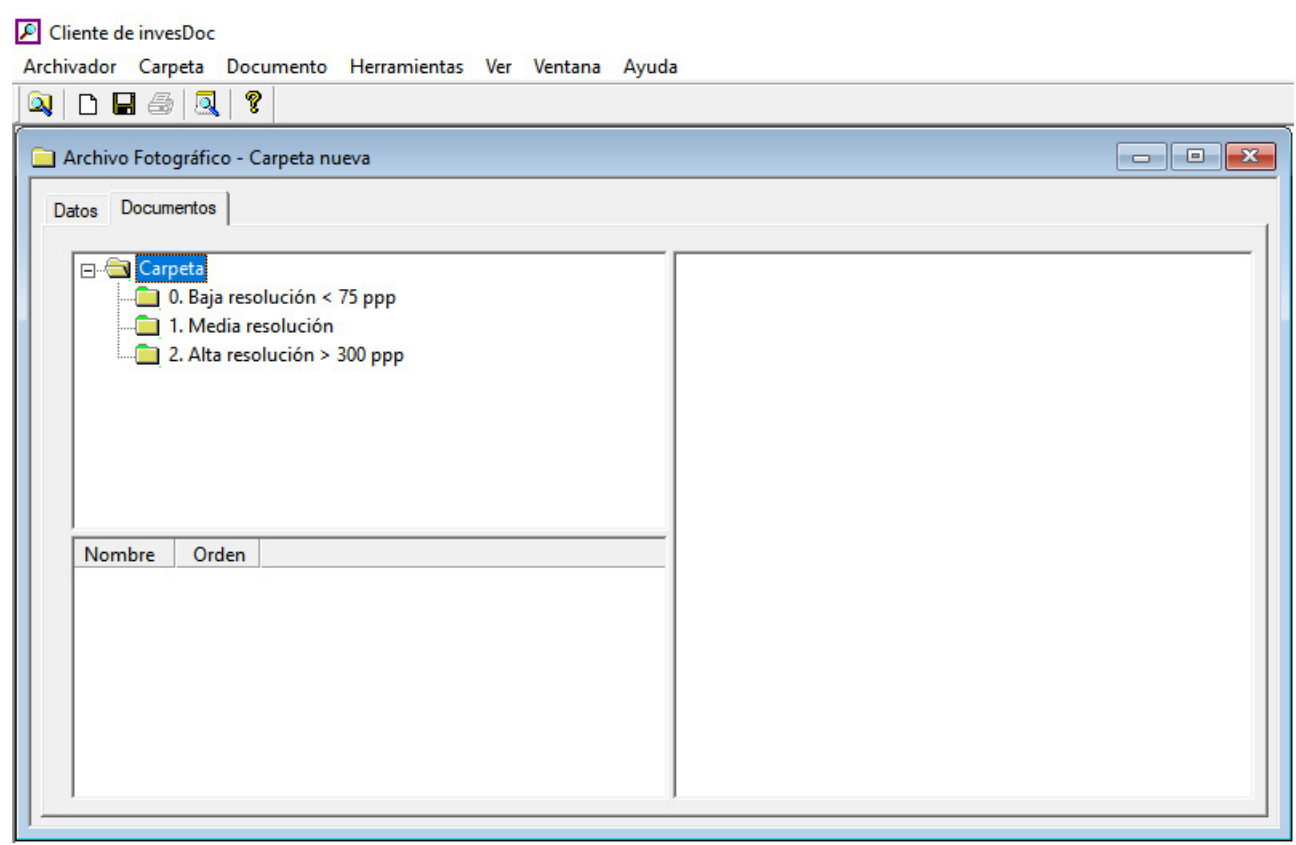

El inventario y posteriormente la catalogación, se dilataron entre los primeros meses de 2008 y el final de la ejecución del proyecto, junio de 2015; aspectos del contenido artístico de la imagen, aquellos que se consideraron necesarios para su correcta catalogación y posibilitar el estudio científico: identificación de la obra, materia o descripción. Por lo que respecta al proceso de digitalización de las fotografías, a lo largo del año 2008 se iniciaron los trabajos con aquellas fotografías que estaban en peor estado y así empezar con la conservación de las mismas.

\section{Ordenación}

Una de las peculiaridades de este archivo ha sido la imposibilidad de la ordenación física de los documentos ya que la custodia física se ha externalizado en la empresa de gestión documental ADEA, a excepción del material gráfico que sí que ha sido ordenado físicamente y digitalizado para su conservación. EL AHR es una agrupación de Fondos, como ya hemos indicado, donde cada empresa forma su propio fondo, y la ordenación de las fotografías ha seguido este mismo Cuadro de Clasificación, por lo que se ha respetado el principio de procedencia de la imagen.

\section{Conservación}

La digitalización de todas las imágenes permite a los empleados e investigadores trabajar con todo el fondo sin tener que manipular las fotografías originales, algunas de ellas en mal estado de conservación. Para solucionar dichos problemas, todas las fotografias se encuentran custodiadas en carpetas de cartón libres de ácidos (con PH 8.5) y resistentes a las plegaduras y oxidación. 
A lo largo del último año de ejecución del proyecto, 2015, y con posterioridad a la conclusión del mismo, los técnicos del AHFR han diseñado una página en la intranet de Repsol que conecta directamente con el sistema de gestión de archivo, para contener todas las imágenes, lo que permite el acceso a este fondo fotográfico y su mayor difusión entre los empleados de Repsol, así como a la comunidad científica interesada. El estudio de estas imágenes dio lugar a presentaciones en distintos actos institucionales, ayuda en la creación de artículos científicos, así como libros específicos de nuestra materia, lo que indudablemente ha colaborado a su mayor difusión y divulgación.

\section{Acceso}

Actualmente contamos con un acceso interno a este archivo, es decir solamente tienen acceso aquellas personas que formen parte de la plantilla del Grupo Repsol y quienes justifiquen un interés en acceder a dichos fondos (investigadores, historiadores, etc). Es más, el empleado tiene acceso al archivo, pero sólo a aquéllas secciones o series de las que es propietario o usuario. De tal forma que no todos los empleados tienen acceso a todos los documentos, incluyendo las fotografías.

\subsection{Acceso virtual}

Todo lo expuesto anteriormente conduce a que actualmente el AHR se encuentre en un momento de gran actividad, fundamentalmente centrado en la catalogación de los documentos. Al comienzo del mes de enero de 2019 se cuenta con 9.215 documentos en papel y 4.015 fotografías en papel, todo ello digitalizado.

Esquema de conexiones que posibilita la consulta integrada vía la intranet de Repsol. Memoria CDTI.

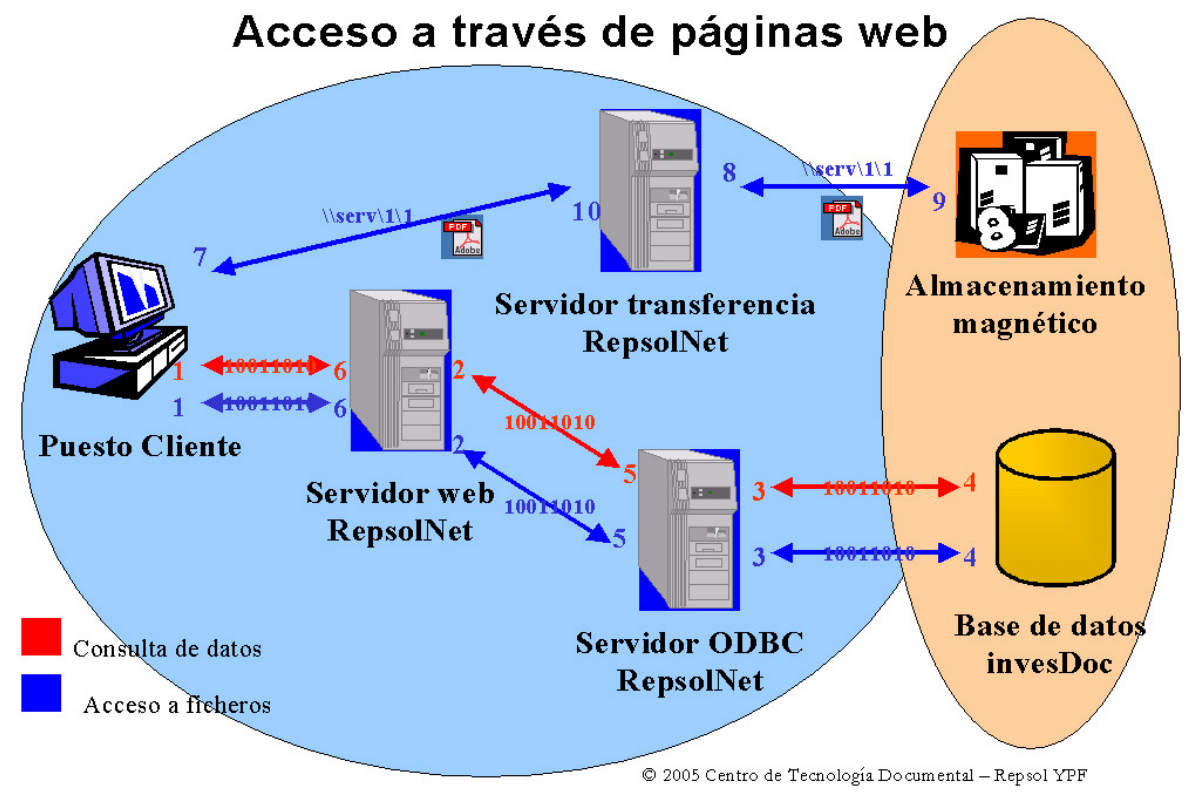


Uno de los objetivos de este proyecto, en el que han trabajado cinco personas desde el año 2007, ha sido la puesta a disposición de dicha documentación para todos los empleados de Repsol como primer paso para posteriormente, poner dicho Archivo a disposición de los investigadores y de la sociedad en general, como ya hemos mencionado.

Ficha de visualización del AHFR a través de Repsolnet.

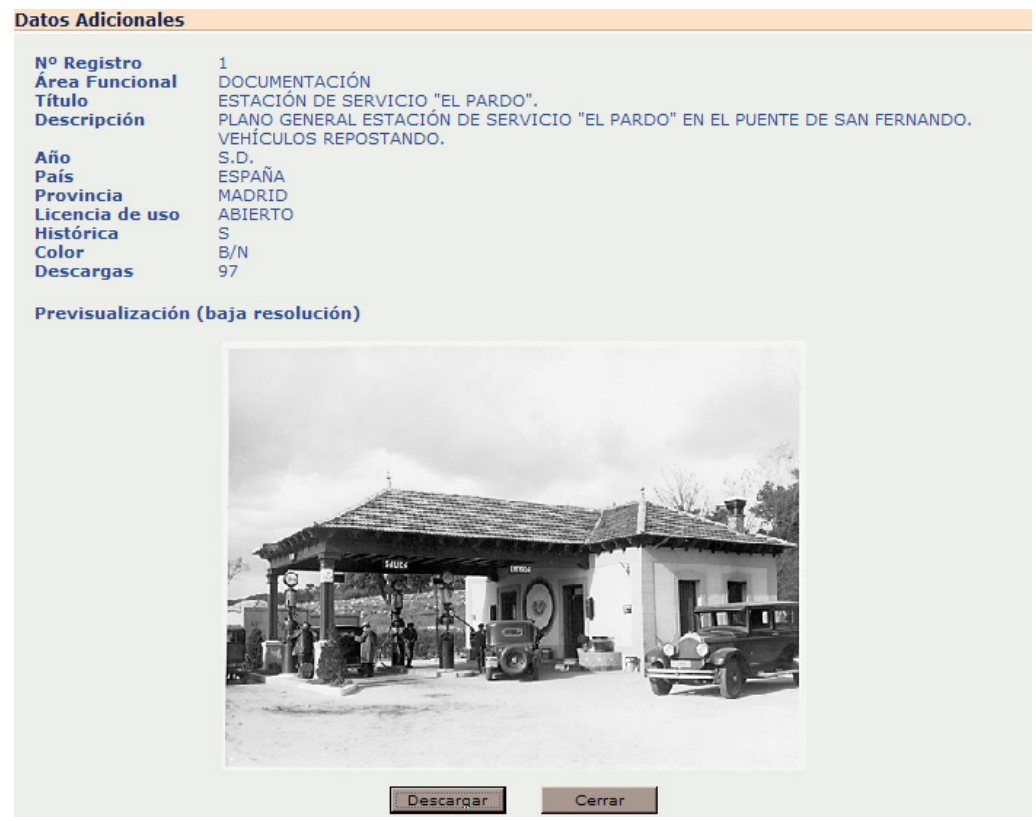

Para la difusión de estos documentos, la herramienta utilizada fue la intranet de Repsol denominada Repsolnet. Lo que se pretendía es que el usuario se encontrara con un archivo histórico amigable, con campos muy sencillos de búsqueda y sobre todo que le ayudara en su trabajo, para lo cual la digitalización de los documentos era un objetivo prioritario.

Una vez que se tuvo una muestra representativa de la documentación de nuestro Archivo, se decidió que una parte del mismo, el archivo fotográfico, sería un maravilloso escaparate para este proyecto y se decidió empezar a trabajar con este material paralelamente a otros tipos documentales.

Para que dicha difusión y por tanto el acceso fuese lo más sencillo posible, se diseñaron dos modelos de búsqueda:

- Parámetros de consulta. - con seis elementos de búsqueda, donde cinco de ellos (Fondo, Sección, Serie, Año y Tipo de Documento) están tabulados, es decir tienen unos valores predefinidos, y uno de ellos, el campo título es de búsqueda libre.

- Estructura de árbol. -los fondos de las empresas, así como las secciones y series se encuentran bajo una estructura arbórea para facilitar la búsqueda al usuario. Se trata realmente de la búsqueda utilizando el Cuadro de Clasificación del archivo. Este sistema se utiliza un $60 \%$ más que el anterior. 
Durante el primer mes que se puso este archivo fotográfico a disposición de los usuarios, tuvo más de 5.000 visitas, lo que nos animó a poner no solamente una parte del mismo, sino en su globalidad, todo el archivo histórico, restringiendo, en ocasiones, tipos documentales como por ejemplo las actas de Comités de Dirección, que tienen que solicitarse directamente a la Unidad de Archivo.

Ejemplo de Acta con acceso restringido.

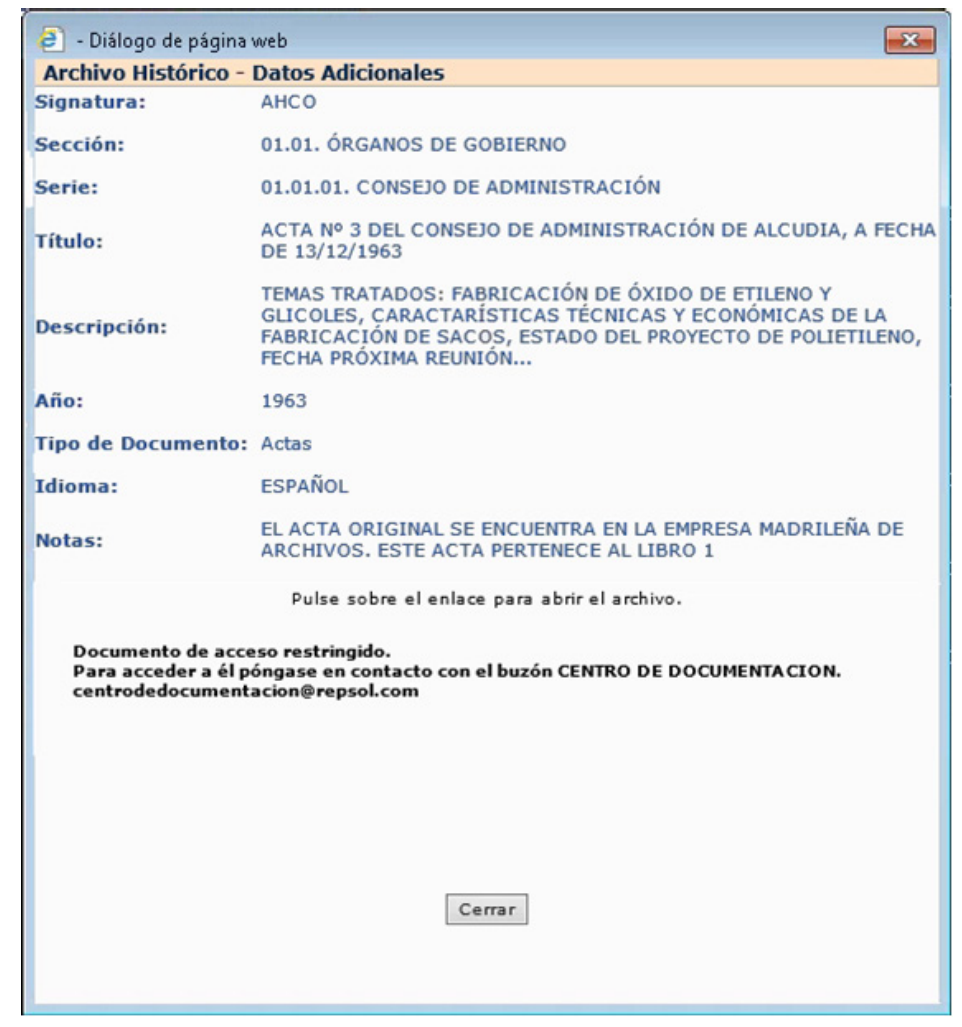

Se quería ofrecer toda la información posible, no solamente de forma referencial sino también a texto completo, lo que significó la digitalización de más de 8.000 documentos relacionados entre sí, por lo que el contenido de un expediente, actualmente se puede consultar a partir de una misma ficha catalográfica.

\section{Conclusiones}

1. Como se ha expuesto en este artículo nos encontramos con un sector que ha sufrido numerosos cambios societarios principalmente en el siglo XX.

2. Fruto de tantos cambios, se ha generado una documentación heterogénea, custodiada en el Archivo Histórico de Repsol, que no sólo es reflejo de la historia de esta institución, sino que es reflejo de una sociedad que ha pasado de una dictadura al libre mercado. 
3. El material que se custodia en el Archivo Histórico Fotográfico de Repsol permite el estudio de la sociedad española a través de sus empresas que en el caso de Repsol lleva asociado pueblos donde los trabajadores vivían (los denominados poblados).

4. Repsol ha finalizado la digitalización de sus fondos históricos al tiempo que obtiene las imágenes actuales con cámaras digitales. Siendo el formato digital el único formato con el que se trabaja en la actualidad.

\section{Anexo 1. Índice de Abreviaturas}

\begin{tabular}{|c|c|}
\hline AHR & ARchivo Histórico Repsol. \\
\hline AHFR & ARCHIVO HistóRICO FotográFICO REPSOL. \\
\hline CAMPSA & Compañía Arrendataria del Monopolio de Petróleos S.A. \\
\hline CEE & COMUNIDAD ECONÓMICA EUROPEA \\
\hline CDTI & Centro para el Desarrollo Tecnológico Industrial. \\
\hline EMPETROL & Empresa Nacional del Petróleo. \\
\hline ENCASO & EMPRESA NaCiONAL DE COMBUSTIBLES LíQuidOS y LUBRICANTES. \\
\hline ENIEPSA & EMPRESA NACIONAL DE InVESTIGACIÓN Y EXPlotaCión DE Petróleos, S.A. \\
\hline ENTASA & Empresa Nacional de Petróleos de Tarragona, S.A \\
\hline HISPANOIL & Hispánica de Petróleos. \\
\hline INH & INSTITUTO NACIONAL DE HIDROCARBUROS. \\
\hline INI & InSTITUTO NACIONAL DE INDUSTRIA. \\
\hline PETROLIBER & Compañía Ibérica Refinadora de Petróleos, S.A. \\
\hline REPESA & Refinería de Petróleos de Escombreras, S.A. \\
\hline
\end{tabular}

\section{Bibliografía}

Cabañas Bravo, Miguel. «El Archivo Fotográfico de Arte del CSIC tras 1939. Herencia, continuidad y uso en el estudio y protección del patrimonio artístico español» en Colorado Castellary, Arturo (ed.) Patrimonio cultural, guerra civil y postguerra. Madrid: Editorial Fragua, 2018. p.305-341.

Castro Leal, Leticia de. «El Archivo Histórico de Repsol YPF: creación y digitalización». Revista de la Asociación de Archiveros de la Comunidad de Madrid. 2008, nº 3, p.36-45.

Castro Leal, Leticia de y Lerena Robles, Iván «La memoria histórica en el sector de los hidrocarburos» en Actas del VIII Congreso de ANABAD. Madrid: Boletín de la ANABAD, 2008, no 4 , p. 197-204

Cruz Mundet, José Ramón. «Archivo y empresa: más allá de la historia». Transporte, Transportes, Servicios y Telecomunicaciones. v.1 p.187-206

Dewerpe, Alain (1987). «Miroirs d'usines: photographies industrielles et organisation du travail à l'Ansaldo (1900-1920)». Annales. Économies, Sociétés, Civilisations, nº5, p.10791114.

Heredia Herrera, Antonia. Archivistica General: Teoría y Práctica. $5^{a}$ ed. Sevilla: Diputación. Servicio de Publicaciones, 1999. p.512

Ibáñez, R. [et al.] «El Archivo Fotográfico en la Unidad de Tratamiento Archivístico y Documentación 338 Referencias (UTAD) del Centro de Ciencias Humanas y Sociales del 
CSIC». en Actas XI Jornadas de Gestión de la Información. Madrid: SEDIC, 2009. p. 225-236.

Magnien, Agnès. El Instituto Nacional del Audiovisual de Francia (INA) y la gestión de los archivos de televisión en el entorno digital. Documentación de las Ciencias de la Información, n41, p.7-18. DOI: https://doi.org/10.5209/DCIN.62105 [consultado 01/08/2019]

Martínez Abascal, Eduardo y Rahnema, Ahmad. La privatización de Repsol. Caso de estudio. Navarra: IESE, 1994.

Montiel Roig, Gonzalo (2015). «La fotografía industrial y el archivo de empresa en la siderurgia del Puerto de Sagunto: representación, poder e identidad (1944-1976)». Revista Española de Investigaciones Sociológicas, 149: 65-86. DOI: http://dx.doi.org/10.5477/ cis/reis.149.65 [consultado 01/08/2019]

Pinto Molina, María; García Marco, Francisco Javier y Agustín Lacruz, Carmen. Indización y Resumen de Documentos Digitales y Multimedia: Técnicas y Procedimientos. Gijón: Ediciones Trea, 2002.

Prussat, Margrit. «Reflexions on the Photographic Archive in the Humanities» en Helff, S. y Michels, S. Global Photographies. Memory - History - Archives. Transcipt Verlag, 2018 p.133-153. DOI: https://doi.org/10.25969/mediarep/1677. [consultado 01/08/2019]

Sánchez Vigil, Juan Miguel. «La fotografía como documento en el siglo XXI». Documentación de las Ciencias de la Información, 2001, n²4, p.255-267

Tortella Gabriel, Ballestero Alfonso y Díaz Fernández, José Luis. Del Monopolio al Libre Mercado: la historia de la industria petrolera española. Madrid: LID Editorial Empresarial, 2003. p.632

Valle Gastaminza, Félix del, ed., Documentación fotográfica. Madrid: Síntesis, 1999. p.255

Valle Gastaminza, Félix del. «Indización y representación de documentos visuales y audiovisuales». en López Yepes, J. (coord.). Manual de Ciencias de la Documentación. Madrid: Pirámide, 2002. 